\title{
Effects of Self-Care Education with Telephone Follow-up on Self-Efficacy level in Hemodialysis Patients
}

\author{
Marzieh Kargar Jahromi ${ }^{1}$, Farzad Poorgholami ${ }^{2 *}$, \\ Farzad Rahmanian $^{3}$ and Elham Rahmanian ${ }^{4}$
}

\author{
${ }^{1}$ Research center for non-Communicable Diseases, \\ Jahrom University of Medical Sciences, Jahrom, Iran. \\ ${ }^{2}$ Medical-Surgical Nursing, Faculty Member, Jahrom University of Medical Science, Jahrom, Iran. \\ ${ }^{3}$ Department of Student Research Committee, Jahrom University of Medical Sciences, Jahrom, Iran. \\ ${ }^{4}$ Cellular and Molecular Gerash research center, Gerash School of Medical Science, \\ Shiraz University of Medical Science, Shiraz, Iran.
}

http://dx.doi.org/10.13005/bbra/2043

(Received: 01 January 2016; accepted: 23 February 2016)

\begin{abstract}
Introduction: Patients under hemodialysis treatment face various physical and mental problems. One of the basic principals in prevention of complications in these patients is education. But education, solely, does not result in improve hemodialysis control situation, therefore, more attention should be paid to follow-up. Currently, by coming new communications systems and telemedicine, using them, such as follow-up methods, is inevitable. This study aimed to determine the effect of self-care education with telephone follow-up on the self-efficacy level in hemodialysis patients. This study is a quasiexperimental study conducted from October 2013 to March 2014 recruiting 60 hemodialysis patients referring to dialysis ward, Motahhari Hospital, Jahrom, Iran. The data collection instruments included demographic questionnaire and SUPPH (Strategies Used by Patients to Promote Health). The data were collected in two steps, before and two months after training intervention. Questionnaires were completed in interview method by research assistance. At the first, participants took part in 5 consecutive one-hour training instructions and then they received an instruction booklet. Then 60 patients were randomly assigned into two groups including self-care training group (30 patients) and self-care training with telephone follow-up group (30 patients). The self-care training with telephone follow-up group was received 24 phone calls (three times a week during the first and second months after the instruction) in addition to receiving 5 instructional sessions and instruction booklet. Phone call schedule was given in writing to the patients after the fifth session of instruction. The duration of each call was 20 minutes, which could also vary according to the patients' needs. The data were analyzed by SPSS version 20, Chi-square, Paired $t$ and Independent $t$ tests. There were no statistically significant differences in demographic variables between the groups. Pre-test mean scores for self-efficacy did not differ between the groups. There was a significant difference between the self-care training with telephone follow-up group and selfcare training group in terms of pre-to post-intervention changes in overall self-efficacy scores, stress reduction, and decision making $(\mathbf{p}<\mathbf{0 . 0 0 1})$. Our study demonstrates that a combination of self-care training and telephone follow-up improves self-efficacy in hemodialysis patients. self-care training with telephone follow-up should be considered in hemodialysis centers to assist patients with the management of their health-related problems.
\end{abstract}

Keywords: Hemodialysis, Patient Education, Self-Efficacy, Telephone, Follow-up.

Kidney failure is a chronic disease that its prevalence in the world is reported 242 cases

* To whom all correspondence should be addressed. per one million and annually 8 percent will be added to this amount. This rate varies in different countries so that the statistic is 758 and 180 people per one million in Negroes and in white-skinned people, respectively ${ }^{1,2}$. Treatment with 
hemodialysis is currently the most common treatment for the disease in all around the world ${ }^{3}$. Approximately one million people in the world are treated with by this method ${ }^{4}$. Patients under hemodialysis are experiencing multiple problems. The main problems are sleeping disorders, peripheral neuropathy, infection, mental stress, anxiety and depression, cognitive changes, wanness, changing skin color, and skin brittleness ${ }^{5,10}$. These various problems influence on different aspects of quality of life in patients undergoing hemodialysis. Patients undergoing hemodialysis due to the long-term process of treatment, require a change in their lifestyle in order to better cope and manage their disease. Treatment of these patients cannot be effective, and desired results cannot obtain without patient's own participation and without doing some self-care activities ${ }^{11}$. So self-care and self-efficacy are fundamental concepts in this group of patients. Self-efficacy is a concept that has larger dimension of self-care and is considered in undergoing hemodialysis patients ${ }^{12}$. Self-efficacy means having a conviction for doing behavior successfully to create optimal and pleasant outcome $^{13}$. Bandura (1986) defines self-efficacy as "people's judgments of their capabilities to organize and execute courses of action required to attain designated types of performances" ${ }^{\prime 14}$. Bandura (1997) defines the key challenges leading to the role of self-efficacy belief in human functioning. "People's level of motivation, affective states, and actions are based more on what they believe than on what is objectively true". He calls the process of creating of short- and long-term goals as "mastery guide"; he knows experiences and services as a great meaning for developing and extension of behavioral competencies that is an effective technique to increase people's selfefficacy ${ }^{14}$. Pandora suggest that self-efficacy is a productive power that by which cognitive, social, emotional and behavioral skills of human are regulate effectively to achieve different objectives. In his viewpoint, having knowledge, skills and previous achievements of individuals are not suitable predictors for future performance of individuals, but believe of human about own capabilities in doing them is effective on quality of own performance. There is a clear difference among having various skills with combination power of them by suitable methods for doing tasks in different conditions ${ }^{15}$. Previous studies show that people, who are confident of their capabilities, actively take part in hygiene programs for promoting health level and participation in hygiene programs will enhance quality of life $\mathrm{e}^{16}$.

Previous studies found that follow-up is one of the most efficient protection methods (hygiene programs for promoting health level), which has proven its effectiveness in solving problems of client and by which assistant puts true and correct information to the client ${ }^{17}$. Telephone follow-up is a kind of the use of technology for caring clients and is applied for self-assessment, monitoring, decision making and giving necessary recommendations. It is planned on the base of patient care needs when the patient is not available. Patients in this method share their physical performance condition with minder, and necessary attention presents to them by telephone according to their age, gender and health problems ${ }^{17}$. Various studies indicate that telephone calls by nurse have been effective in improving some disease outcomes such as orthopedic surgeries, bypass and cancer ${ }^{17}$.

Given to this problem that telephone follow-up is a very useful and inexpensive method to assess the out-of-hours needs of patients' care and cause reduction in frequent examinations ${ }^{17}$. With this technology very useful care intervention can be performed in a short time and the hospital based cares can convert to the client base cares. Thus, according to the needs of hemodialysis patients to an available care system and given to a few performed studies in this field, the present study was carried out by the aim of investigation on the impact of self-care education by telephone follow-up on self-efficacy level in hemodialysis patients.

\section{METHODANDMATERIAL}

\section{Study Design and Sample}

This is a single-blind randomized clinical trial recruiting 60 hemodialysis patients who referred to Dialysis Ward, Motahhari Hospital, Jahrom University of Medical Sciences, Jahrom, Iran. The study was conducted from October 2013 to March 2014. Patients were recruited through convenience sampling method. Inclusion criteria 
included age of 18-65 years, having at least the ability to read and write, final stage renal disease, being at least 6 months on hemodialysis for three times a week for three to four hours, and not renal transplantation or immigration during intervention, and not participating in any educational class out of the routine ones for at least during the last year, and no cognitive and psychological disorders. Exclusion criteria included a history of serious or adverse experiences in the last six months, treatment with antidepressant medications, hospitalization due to acute disease, and unwillingness to participate or to continue with the study.

\section{Instrument}

A two-part questionnaire was used for data collection. The first part included seven questions on patients' demographic characteristics including age, sex, marital status, employment, education level, income level, and hemodialysis frequency in a week. The second part was the SUPPH (Strategies Used by Patients to Promote Health). Self-care self-efficacy was measured by a 29-item self-reported questionnaire. The first version of this questionnaire (SUPPH) was developed based on the self-efficacy theory and includes four dimensions: coping, stress, decision making, and enjoying life. In another study dimensions of the instrument were reduced to three: positive attitudes (16 questions), stress (10 questions), and decision making (3 questions) ${ }^{18}$. The latter questionnaire was translated into Persian (Farsi) and back-translated into English to ensure its validity, which was further confirmed by a panel of experts. Next, the instrument was distributed to 30 representative patients for measurement of reliability. Cronbach's alpha for the overall questionnaire was 0.91 and for the dimensions of the instrument, it was as follows: stress reduction (0.79), decision making (0.8), and positive attitude (0.87). Reliability of the original form in these dimensions was reported as 0.89 (stress reduction), 0.83 (decision making), and 0.92 (positive attitude) (19-20). Possible scores for the overall self-care self-efficacy questionnaire were 29 - 145. The ranges for the dimensions were: positive attitude (16 - 80), stress (10 - 50), and decision making (3 15). Higher scores reflect better outcomes.

\section{Intervention}

This study was approved by the Research Council and the Research Ethics committee of Jahrom University of Medical Sciences. Data collection was performed after explaining the research objectives, and obtaining written informed consent from the participants. All patients were assured of obscurity and confidentiality of their personal information, and the right to refuse participation or withdraw from the study at any time. Also the necessary permissions were sought from the hospital authorities and the hemodialysis unit. Sixty patients were finally recruited in the trial, 30 in each group, by considering a possible attrition. The questionnaires were completed by patients before the intervention. At the first, participants took part in 5 consecutive one-hour training instructions and talking subjects were about familiarity with the disease process, hemodialysis importance and familiarity with diet, limitation in fluid intake, daily control of body weight, physical activity, how to control vital signs, familiarity with the symptoms of causing the disease, importance of stopping smoking, stress management and muscular relaxation and moreover they received an instruction booklet. Then 60 patients were randomly assigned into two groups including self-care training group (30 patients) and self-care training with telephone follow-up group (30 patients). The self-care training with telephone follow-up group was received 24 phone calls (three times a week during the first and second months after the instruction) in addition to receiving 5 instructional sessions and instruction booklet. Phone call schedule was given in writing to the patients after the fifth session of instruction. The duration of each call was 20 minutes, which could also vary according to the patients' needs. The content of the call followed a script to ensure consistency. The telephone follow-up consultations included the issues, which had been taught in the five-sessions-instruction and had been mentioned in the booklet as well as answers to the patients' questions. In addition, the patients were told that they could call the researcher any time for their any questions. All the follow-ups calls were made by the researcher. Finally the SUPPH questionnaire was filled out by the patients after completion of study by two groups. 


\section{Data Analysis}

The data was analyzed by SPSS software version 20 and also descriptive and analytic statistics including Independent-Samples $\mathrm{T}$ test, Chi square, Paired t-Test and analysis of variance.

\section{RESULTS}

In total, 54 patients completed the study. Despite the attempt of researchers to prevent attritions of samples through attending in the field and telephone follow up, but some of the patients did not complete the study. During the research, three patients in the control group and three patients in the intervention group (two due to major complications, two patient due to inaccessibility by the researcher, and two patients because of declining to do hemodialysis) were excluded from the study.

Table 1. Relative frequency distribution of the research units based on demographic variables in the two groups

\begin{tabular}{|c|c|c|c|c|}
\hline $\begin{array}{l}\text { Groups } \\
\text { Characteristics }\end{array}$ & $\begin{array}{l}\text { Trainning with } \\
\text { Telephone } \\
\text { Follow-up }\end{array}$ & $\begin{array}{l}\text { Self-Care } \\
\text { Trainning } \\
\text { Relative } \\
\text { Frequency }\end{array}$ & $\begin{array}{l}\text { Self-Care } \\
\text { Relative } \\
\text { Frequency }\end{array}$ & $\begin{array}{c}\mathrm{P} \\
\text { Values }\end{array}$ \\
\hline Gender & $\begin{array}{l}\text { woman } \\
\text { man }\end{array}$ & $\begin{array}{l}56 \% \\
44 \%\end{array}$ & $\begin{array}{l}40 \% \\
60 \%\end{array}$ & 0.32 \\
\hline Marital Status & $\begin{array}{l}\text { Single } \\
\text { Married }\end{array}$ & $\begin{array}{l}28 \% \\
72 \%\end{array}$ & $\begin{array}{l}16 \% \\
84 \%\end{array}$ & 0.47 \\
\hline HavingEmployment & $\begin{array}{l}\text { Yes } \\
\text { no }\end{array}$ & $\begin{array}{l}40 \% \\
60 \%\end{array}$ & $\begin{array}{l}56 \% \\
44 \%\end{array}$ & 0.62 \\
\hline Level of Education & $\begin{array}{l}\text { Primary } \\
\text { Junior high school } \\
\text { high school } \\
\text { Academic }\end{array}$ & $\begin{array}{c}4 \% \\
36 \% \\
56 \% \\
4 \%\end{array}$ & $\begin{array}{c}4 \% \\
36 \% \\
48 \% \\
12 \%\end{array}$ & 0.43 \\
\hline $\begin{array}{l}\text { The Number of Hemodialysis } \\
\text { in Week }\end{array}$ & $\begin{array}{l}\text { Two times } \\
\text { Three times }\end{array}$ & $\begin{array}{l}20 \% \\
80 \%\end{array}$ & $\begin{array}{l}28 \% \\
72 \%\end{array}$ & 0.57 \\
\hline Level of Income & $\begin{array}{l}\text { Weak } \\
\text { Average } \\
\text { Good }\end{array}$ & $\begin{array}{l}36 \% \\
52 \% \\
12 \%\end{array}$ & $\begin{array}{c}20 \% \\
72 \% \\
8 \%\end{array}$ & 0.62 \\
\hline
\end{tabular}

Table 2. Comparison of mean and standard deviation of self-efficacy scores in the studied groups, before and after intervention

\begin{tabular}{|c|c|c|c|c|c|}
\hline \multirow[t]{3}{*}{ Groups } & \multicolumn{2}{|c|}{$\begin{array}{l}\text { Self-Care trainning with } \\
\text { Telephone Follow-up }\end{array}$} & \multicolumn{2}{|c|}{ Self-Care trainning } & \multirow{3}{*}{$\begin{array}{l}\text { ANOVA } \\
\text { test } \\
\text { P- value }\end{array}$} \\
\hline & Before & After & Before & After & \\
\hline & Intervention & Intervention & Intervention & Intervention & \\
\hline Self-Efficacy & Standard & Standard & Standard & Standard & \\
\hline Aspects & $\begin{array}{l}\text { Deviation and } \\
\text { Mean }\end{array}$ & $\begin{array}{l}\text { Deviation and } \\
\text { Mean }\end{array}$ & $\begin{array}{l}\text { Deviation and } \\
\text { Mean }\end{array}$ & $\begin{array}{l}\text { Deviation and } \\
\text { Mean }\end{array}$ & \\
\hline Stress & 18.480 & 48.440 & 18.000 & 24.840 & $0.001<$ \\
\hline reduction & 2.600 & 2.416 & 3.188 & 3.131 & \\
\hline Decision & 5.040 & 19.280 & 5.200 & 8.120 & $0.001<$ \\
\hline Making & 1.019 & 1.720 & 1.000 & 1.013 & \\
\hline Positive & 25.960 & 75.080 & 25.480 & 38.240 & $0.001<$ \\
\hline Attitude & 2.715 & 4.654 & 3.203 & 3.152 & \\
\hline \multirow[t]{2}{*}{ Total Score } & 49.480 & 127.800 & 48.680 & 68.200 & $0.001<$ \\
\hline & 5.124 & 5.656 & 6.920 & 5.838 & \\
\hline
\end{tabular}

Note. significance level considered by $\mathrm{P}<05$ 
Table 1 demonstrated socio-demographic characteristics of the patients. The mean age of participants was 69.13 (SD=11.82); Chi-square test showed that both groups were similar in terms of socio demographic characteristics.

According to Table 2, a significant percentage of hemodialysis patients in both the
Self-Care trainning and Self-Care trainning with Telephone Follow-up groups before intervention had a low level in self-efficacy. Also increase of different aspects in self-efficacy was observed after intervention in the Self-Care Education with Telephone Follow-up group compared with the Self-Care Education group. $(\mathrm{p}<0.001)$.

According to Table- 3, it was found that

Table 3. Comparisons of self-efficacy total scores between the both Self-Care training with Telephone Follow-up and Self-Care training groups

\begin{tabular}{|c|c|c|c|}
\hline Different Aspects & Group & $\begin{array}{l}\text { Mean } \\
\text { Difference }\end{array}$ & $\begin{array}{l}\text { P-value } \\
\text { Scheffe Test }\end{array}$ \\
\hline Stress reduction & $\begin{array}{l}\text { Self-Care training with Telephone } \\
\text { Follow-up - Self-Care training }\end{array}$ & 23.600 & $0.001<$ \\
\hline Decision Making & $\begin{array}{l}\text { Self-Care training with Telephone } \\
\text { Follow-up - Self-Care training }\end{array}$ & 11.160 & $0.001<$ \\
\hline Positive Attitude & $\begin{array}{l}\text { Self-Care training with Telephone } \\
\text { Follow-up - Self-Care training }\end{array}$ & 36.840 & $0.001<$ \\
\hline
\end{tabular}

there is significant difference in comparison of selfefficacy total scores between the Self-Care training with Telephone Follow-up and Self-Care training groups.

\section{DISCUSSION}

The results show that Self-Care training with telephone follow-up in the Self-Care training with Telephone Follow-up group can increase different aspects of self-efficacy such as relieve of stress, decision-making and positive attitude. As it is observed in Table 2, the results related to comparison of average of self-efficacy before and after the test indicate the positive effect of selfcare with telephone follow-up.

According to the performed studies, patients who have higher self-efficacy involve more in the self-care activities. So the treatment regimens that causes further improve the disease are more accepted by them (21). Also it is stated that selfefficacy is a valuable tool for nurses in health centers and evaluation of self-efficacy by nurses can increase patients' motivation in self-care (19), that is consistent with the results of the present study and increase of self-efficacy will relieve stress and also causes increase in decision-making and positive attitude in the both groups.

Self-efficacy in self-care is positively associated with quality of life and negatively associated with depression. As a result, selfefficacy in a higher self-care leads to lower level of depression and improve of quality of life ${ }^{22}$. In the results of correlated study that had done on 255 patients by Esmaili et al, entitled "quality of life and its relationship with self-efficacy in hemodialysis patients", it was found that there is a direct and significant relationship between two variables, quality of life and self-efficacy. They also stated that nurses by own suitable training in hemodialysis ward can play an important role in increase of confidence of patients in self-care behaviors and consequently in improve quality of life in patients ${ }^{16}$.

According to Bandura's theory selfefficacy includes trust and confidence of individual from own ability in performing ideally self-care so that in this way individual achieve to desired results. Tsay (2003), self-efficacy affects on understanding of function and adaptive behaviors, selection of environment, and conditions in which people try to achieve ${ }^{23}$. That is consistent with the present study.

Findings indicated that receiving of selfefficacy affects on each phase of health behavior changes. Where individuals want to change their health behaviors, how much this health program is useful for them, how much they will maintain the 
achieved changes, and how much their vulnerability subsides. Evidence also suggests that self-efficacy is a medium which affects on psychological-social programs in health conditions.

The self-efficacy theory states that strength of belief in ability of person is a good indicator for motivation and future behavior. In fact, an efficient person believe that can achieve to master capability, modeling, reinterpretation of physiological symptoms and social encourage and finally self-efficacy leads to improve of treatment, motivation, thinking patterns, and improve of emotions $^{24}$.

Self-efficacy as an affecting factor emphasizes quality of life, understanding of person from skills and capabilities in successfully doing of worthy performance. In other words, self-efficacy influences on understanding of performance, adaptive behaviors, selection of environment and conditions in which people try to achieve ${ }^{16}$.

Self-efficacy feeling can affect all aspects of life. For example, investigations show that as much as the level of self-efficacy is higher, the considered domain of job opportunities will be higher and the interest to job will be deeper ${ }^{16}$. So that in the current study the most studied people were employed. Person who are high in terms of self-efficacy believe that they are effectively able to control events of their lives. This understanding and belief give them a different perspective from those that in terms of self-efficacy are weak because this feeling has a direct effect on their behaviors. Thus self-efficacy can be a critical factor in success and defeat throughout the life $\mathrm{e}^{16}$. In the current study, a significant increase in positive attitude was observed in the experimental group after the intervention than before it and in the control group that reflects the positive effects of self-care trainning and also telephone follow-up in increase of self-efficacy and improvement of the disease.

\section{CONCLUSION}

The results of this study showed that telephone follow-up by nurse can improve different aspects of self-efficacy and also disease in hemodialysis patients. In addition this method is an effective and convenient procedure for elderly patients and patients who are not able to refer to health centers. So patients training is recommended for continues use of this effective treatment method.

\section{REFERENCES}

1. Bard R. A team approach to better care. Can Nurse 2010; 106(1): 3.

2. Poorgholami F, Javadpour SH, Saadatmand V, Kargar Jahromi M. Effectiveness of Self-Care Education on the Enhancement of the SelfEsteem of Patients Undergoing Hemodialysis. Global Journal of Health Science. 2016; 8(2): 132-136.

3. Kimmel PL, Peterson RA. Depression in patients with end-stage renal disease treated with dialysis: has the time to treat arrived? Comment on Clin J Am SocNephrol 2006;1(3):349-52.

4. Bamgboye EL. Hemodialysis: management problems in developing countries, with Nigeria as a surrogate. Kidney IntSuppl 2003; 63:93-5.

5. Kargar Jahromi M, Javadpour SH, Taheri L, Poorgholami F. Effect of Nurse-Led Telephone Follow ups (Tele-Nursing) on Depression, Anxiety and Stress in Hemodialysis Patients. Global Journal of Health Science. 2016; 8(3): 168-173.

6. Domrongkitchaiporn S, Sritara P, Kitiyakara C, Stitchantrakul W, Krittaphol V, LolekhaP et al. Risk factors for development of decreased kidney function in a Southeast Asian population: a 12-year cohort study. J Am SocNephrol 2005; 16(3):791-9.

7. Akyuz F, Besisik F, Pinarbasi B, Demir K, Kaymakoglu S, Cakaloglu Y et al.The quality of life in hemodialysis patients with chronic hepatitis C virus infection. Turk J Gastroenterol 2009; 20 (4): 243-6.

8. Akman B, Ozdemir FN, Sezer S, Iu M, Haberal M. Depression levels before and after renal transplantation. Transplant Proc 2004; 36:(1).111-3.

9. Brenner BM, Rector FC. Brenner \& Rector's the kidney. 8th Ed. Philadelphia: Saunders Elsevier; 2008; 2241.

10. Urden L, Stacy K, Lough M. Thelan's critical care nursing: diagnosis and management.5th Ed. St. Louis, MO: Mosby; 2006; 1247.

11. Cowen PS, Moorhead S. Current issues in nursing. $7^{\text {th }}$ Ed. Edinburgh: Elsevier Mosby; 2006. P.865.

12. Strauser DR, Kets K, Keim J. The relationship between self efficacy/locus of control and work personality. J ClinNurs 2002; 68 (5): 20-7. 
13. Hutchison A,Hispanicwomens level of selfefficacy and its relationship to their risk for osteoporosis. The Ohio state University. 2008.

14. McGowan P. Self-management: a background paper. University of Victoria Center on Aging. New Perspectives: International Conference on Patient Self-Management held in Victoria, BC in September 2005p: 1-10.

15. http://imi.ir/tadbir/radbir-168/article-168/4.asp

16. Esmaeili M, Alikhani M, KhollamAraghei M, Hossini F. Quality of life and relationship with self- efficacy in patients under hemodialysis. Journal of Nursing.spring and summer 1384; 18(41,42): 78-84.

17. Sadeghi. T, Shahabi Nejad. M, Derakhshan, R, et al., Nurse Telephone Follow-up Impact on Glycosylated Hemoglobin in Diabetic Patients, Journal of Medical Science of Rafsanjan, 20102011; 9 (3): 175-184.

18. Moattari M, Ebrahimi M, Sharifi N, Rouzbeh J, The effect of empowerment on the self-fficacy quality of life and clinical and laboratory indicators of patients treated with hemodialysis: a randomized controlled trial Health and Quality of Life Outcomes 2012; 10: 115.

19. Rambod M. Rafei F. Hossini F. Quality of life in patients with chronic renal failure, Journal of
Nursing and Midwifery Faculty of Tehran university of Medical Sciences (Hayat). 1387; 14(2): 51-61

20. Lev Elise L: Self-efficacy in patients with prostate cancer: Confirmatory factor analysis of Strategies Used by Patients to Promote Health. The 18th Annual Scientific Sessions of the Eastern Nursing Research Society, New Momentum for Nursing Research: Multidisciplinary Alliances, April 21, 2006. 2006. http://hdl. handle.net/10755/163209.

21. Tsay Sh L. Self-efficacy training for patients with end-stage renal disease. Journal of advanced nursing, 2003; 43(3),370-375.

22. Lii Y-C, Tsay S-L, Wang T-S. Group intervention to improve quality of life in hemodialysis patients. Journal of nursing and healthcare of cronic illness in association with journal of clinical nursing. 2007; 16(11):268-275.

23. Malarki L, Mack maro M E. Diagnostic and laboratory tests in nursing. Translate by Peravi H, Honarparvaran N. Tehran, Boshra, 1384: 7188

24. Lorig KR, Holman H. Self management education: history, defiantion, outcomes and mechanisms. Annuals oh behavioral medicine: a Publicationof the Society of Behaviral Meddicine: 2003; 26(1): 1-7 